\title{
Disease Surveillance by Private Health Providers in Nigeria: A Research Proposal
}

\author{
Olusesan A. Makinde ${ }^{\star 1}$ and Clifford O. Odimegwu ${ }^{2}$ \\ ${ }^{1}$ Viable Knowledge Masters, Abuja, Nigeria; ${ }^{2}$ University of the Witwatersrand, Johannesburg, South Africa
}

\section{Objective}

To investigate the compliance of private health facilities to the integrated disease surveillance and response (IDSR) system in Nigeria.

\section{Introduction}

The outbreak of the Ebola Virus Disease (EVD) in Africa in 2014 presented a major threat and concern across the world, spreading to two other continents (Europe and North America). Though the epidemic is on a downward trend, there is a need to evaluate the performance of the systems in place to detect and control such outbreaks and determine the need for improvement in countries affected.

With its first traceable case reported to have been in Guinea, the outbreak spread to Nigeria through an air traveler from Liberia which led to an outbreak in the country that luckily, was quickly contained (1). This imported case was initially managed at a private health facility (PHF) eventually leading to 20 cases and eight deaths, four of which were health workers from the initial managing PHF (1). Despite effort to contact the authorities about the suspected imported case by the PHF, it reportedly took some time before the health authorities could be reached and action at control instituted. This might suggest an inefficiency of the IDSR system which was previously adopted by Nigeria as a means of implementing the International Health Regulation (IHR) of 1969. The IHR is a set of regulations that the World Health Assembly uses to implement its constitutional responsibility to prevent the international spread of diseases.

Hemorrhagic fevers like EVD ought to be reported immediately upon suspicion to the health authorities but the delay despite effort suggests this system is not efficient. This is important as PHFs are noted to attend to over $60 \%$ of the Nigerian population. Thus, it is important to carry out an assessment of the IDSR system in PHFs to forestall a repeat episode and limit the impact of outbreak of infectious diseases in future.

\section{Methods}

This study will be carried out in the South-West of Nigeria where about $40 \%$ of PHFsin the country are located (2). We intend to carry out a mixed-methods study which will include desk reviews, key informant interviews, focus group discussions, analysis of routine data, a cross sectional study of health workers and health facility assessments. Desk review will be completed to understand the legislation and policies establishing the IDSR in Nigeria and opportunities for improvement. Key informants at the federal, state and local government level will be interviewed to understand more about the regulation and implementation of the IDSR across the different levels of governance in the country. Routine health data will be pulled from the national health information system to assess reporting of PHFs. In addition, health facility assessments will be completed along with assessment of the knowledge of health workers in PHFs on the country system for notifiable diseases.

\section{Results}

The study will critically assess the legislation that establishes the IDSR as the means of implementing the IHR in Nigeria. It will provide the status of implementation of the regulation for implementing the IHR. The study will further assess the knowledge of private healthcare providers on the IDSR system in Nigeria and the factors that affect their compliance with this regulation. Furthermore, it will provide information for the readiness of PHFs to report notifiable diseases and will also investigate the differences in reporting rate between public and private health facilities.

\section{Conclusions}

The study will provide a snapshot of the status of PHFs on participation in the IDSR in Nigeria and factors that may be affecting them. It will also highlight areas of inadequate legislation and system failures and will make proposals aimed at addressing these shortfalls.

\section{Keywords}

Surveillance; Communicable Diseases; Research Proposal; Global; Nigeria

\section{References}

1. Shuaib F, Gunnala R, Musa EO, Mahoney FJ, Oguntimehin O, Nguku PM, et al. Ebola virus disease outbreak-Nigeria, July-September 2014. MMWR Morb Mortal Wkly Rep [Internet]. 2014 [cited 2015 Aug 25];63(39):867-72. Available from: http://www.cdc.gov/mmwr/ preview $/ \mathrm{mmwrhtml} / \mathrm{mm} 63 \mathrm{e} 0930 \mathrm{a} 2 . \mathrm{htm}$ ?lang=de

2. Makinde OA, Azeez A, Bamidele S, Oyemakinde A, Oyediran KA, Adebayo W, et al. Development of a Master Health Facility List in Nigeria. Online J Public Health Inform [Internet]. 2014 Oct 16 [cited 2014 Nov 27];6(2). Available from: http://www.ncbi.nlm.nih.gov/ pmc/articles/PMC4235326/

\section{*Olusesan A. Makinde}

E-mail: makindeo@viableknowledgemasters.com 